Las condiciones de posibilidad del teatro argentino interregional como objeto de estudio

Mauricio Tossi

Question, Vol. 1, N.ำ 62, e154, abril-junio 2019

ISSN 1669-6581 | https://doi.org/10.24215/16696581e154

http://perio.unlp.edu.ar/ojs/index.php/question

FPyCS | Universidad Nacional de La Plata

La Plata | Buenos Aires | Argentina

\title{
Las condiciones de posibilidad del teatro argentino interregional como objeto de estudio
}

The conditions of possibility of the Argentine interregional drama as object of study

\author{
Mauricio Tossi mauriciotossi@gmail.com \\ http://orcid.org/0000-0001-5144-2544 \\ Universidad Argentina de la Empresa/ \\ Consejo Nacional de Investigaciones Científicas y Técnicas (Argentina)
}

\section{Resumen}

Los procesos de regionalización en la teoría e historiografía del teatro argentino exponen múltiples desafíos conceptuales y metodológicos. Por este motivo, en este artículo nos proponemos analizar algunos de sus obstáculos epistemológicos y reflexionar sobre las condiciones de posibilidad de las prácticas teatrales regionales como un objeto de estudio 
relevante en el estado actual de la disciplina. Para argumentar a favor de esta estrategia, recurrimos a los aportes teóricos de los estudios culturales, la comparatística y la geografía de lo imaginario, con el fin de construir una red de nociones operativas que justifiquen y orienten un programa de investigación sobre la interregionalización de las producciones históricoescénicas de nuestro país.

Palabras clave: Historiografía teatral; delimitaciones teóricas; regionalización; República Argentina.

\section{Abstract}

The processes of regionalization in the theory and historiography of the Argentine drama expose multiple conceptual and methodological challenges. For this reason, in this article we propose to analyze some of its epistemological obstacles and reflect on the conditions of possibility of regional theatrical practices as a relevant object of study in the current state of the discipline. To argue in favor of this strategy, we look for the theoretical contributions of the Cultural Studies and the Geography of the Imaginary, in order to elaborate a network of operative notions that justify and guide a research program on the interregionalization of the scenic productions of our country.

Keywords: Theatrical historiography; theoretic alboundaries; regionalization; Argentinian republic.

Los trayectos teóricos desarrollados en este artículo se inscriben, entre otras motivaciones, en el reconocimiento de un obstáculo epistemológico que actualmente impacta en la historiografía del arte argentino y, de manera particular, en los estudios de las artes escénicas: la homogeneización de los procesos de regionalización del teatro nacional.

Con el fin de organizar nuestras reflexiones, tomamos como punto de partida una premisa enunciada por Walter Mignolo, quien para argumentar a favor de un pensamiento fronterizo y geopolítico en la investigación literaria afirma: "soy de donde pienso" (2013: 155). Este aforismo condensa una serie de operaciones teóricas que contribuyen a reconocer algunos de los desafíos gnoseológicos asociados a la categoría de teatro regional. Entre otros posibles ejes de lectura, se develan por lo menos dos vectores sobre los que indagaremos a continuación: 1. 
las condiciones de territorialidad de la investigación escénica; 2. las implicancias geoimaginarias en la construccióndel teatro regional como objeto de estudio.

\section{Las condiciones de territorialidad de la investigación escénica}

El debate sobre un pensamiento/acción localizado ha obtenido, en las últimas décadas, numerosos despliegues nocionales y metodológicos, especialmente en la teoría de los estudios culturales, la literatura y las artes visuales (Demaría, 2014; Acha, Colombres y Escobar, 1991). Por lo tanto, siguiendo las investigaciones de los autores que se han ocupado de este tema algunos de ellos serán referenciados en las páginas siguientes- es factible asumir un desafío común: las bases epistémicas de una historiografía por venir, un programa intelectual y político que, entre otras metas, busca dislocar uno de los perfiles del itinerario teórico recorrido en los últimos años, esto es, pasar de una historiografía con tendencia homogeneizante y centralizada hacia una reedición atomizada del estudio de casos provinciales, en la que "lo local de lo local" funda una nueva desproporción o asimetría. Así, el "teatro de provincia" -esto es, el modo de regionalización con mayor alcance y asiduidad disciplinar- se concibe como parte o segmento de la "patria chica", según las coordenadas intersubjetivas de un "otro interior" (Ocampo, 2005: 45).

Comprender y asumir esta advertencia epistemológica emitida desde disciplinas complementarias o auxiliares a los Estudios Teatrales implica reconocer, entre otras variables, la trayectoria de lo que Pablo Heredia ha descrito como un "proyecto intelectual homogeneizador", forjado en nuestro Estado/Nación desde el siglo XIX, consolidado por los principales agentes culturales del Centenario y, luego, actualizado por diversos mecanismos de reproducción ideológica hasta la década de 1960 o, incluso, con remanentes discursivos que llegan hasta nuestros días.

Este proyecto intelectual homogeneizador es el que funda el concepto de "región" y su posterior extensión a las nociones de literatura regional, arte regional o, en nuestro caso, teatro regional. Dicho programa político-cultural se define por una serie de operaciones nacionalistas, siendo el "regionalismo" una de sus variantes dentro de las concepciones criollistas. Así, Heredia, quien ha analizado en detalle este proceso histórico-literario caracterizado por una hegemonía centralista que determina aquello que puede o no ser "regionalizable", dice:

Nación-región será la fórmula nacionalista que elabora la clase dirigente para sostener su poder, como la salida ideológica que le permitiría resistir los embates de las prácticas políticas, ideológicas y culturales que la inmigración llevaba a cabo en la ya por entonces 
Capital Federal. El regionalismo era una textualidad matrizada por un programa narrativo cuyo eje retórico es la "mostración-demostración" de una supuesta identidad regionalnacional que en realidad estaba dirigida a una otredad (los lectores de Buenos Aires) que debía contemplar, comprender y aceptar los valores que ponía en juego su región: la argentinidad responsable (con una historia, una cultura y un territorio donde se había nacido) para instaurar la modernidad en el país (2012: 30-31).

Desde este punto de vista, la histórica categoría de "región" fue elaborada -siguiendo el concepto de Raymond Williams (1980: 137)- como una "tradición selectiva", pues el discurso metropolitano conformó una versión intencionalmente figurada del pasado y, a su vez, formalizó un presente y un futuro preconfigurados, los que resultaron operativos a su diagnóstico de los procesos culturales. De este modo, la región o las regiones -en nuestro caso, las zonas geopolíticas no centralizadas del país- tienen, desde sus fuentes historiográficas, una relación de dependencia identitaria con lo capitalino/portuario, de tal modo que el punto nodal de su estudio está condicionado por la mirada legitimante del centro y por su representación como una diferencia que le garantiza a la metrópolis su alteridad.

Por consiguiente, el principio constitutivo de lo regional -desde esta perspectiva históricaconlleva a los extensos debates de dos constantes: primero, las formaciones canónicas, es decir, las formas modélicas de auto-organización del arte con proyecciones estéticas e ideológicas; segundo, los modos de producción asociados a la dicotomía centro/periferia. Redundar sobre estos dilemas no es el objetivo de este trabajo, por el contrario, tal como planteamos en párrafos posteriores, intentamos superar sus obstáculos epistemológicos con la declaración de un programa teórico-metodológico que nos permita avanzar -sin caer en reduccionismos estériles- en la historia de los teatros regionales no-centrales.

Con el propósito de aproximarnos a esta meta, recuperamos para la historiografía de "los teatros argentinos" (Finzi, 1992: 52) los aportes de la geopolítica del conocimiento propuestos por Walter Mignolo y, a su vez, las nociones operativas de los análisis culturales de Zulma Palermo (2012: 67-71), en especial, su concepto de "lugarización" o locus de enunciación, pues a través de estos progresos disciplinares podemos describir dos desafíos epistemológicoteatrales en la aplicación de la premisa "soy de donde pienso". A saber:

1. La puesta en acción de una epistemología "lugarizada", en la que se indague en la localización geohistórica de las prácticas escénicas e intelectuales. Esta apuesta gnoseológica inicia con la auto-observación crítica de dos variables: por un lado, la conciencia sobre la alteridad que la tradición homogeneizante antes descrita ha proyectado, por ejemplo, en la noción "teatro del interior", esto es, una construcción discursiva que arrasa con las distinciones 
identitarias regionales, a partir de la reproductividad institucional de un "otro" designado prioritariamente para legitimar a un "sí mismo". De este modo, las prácticas artísticas pierden sus ejes cardinales, pues se ponen al servicio de ejes axiológicos, jerárquicos y subyugantes. Por otro lado, en esta epistemología lugarizada para un teatro regional es ineludible una crítica a la noción de modernidad, dado que "lo moderno" no es -como indica Walter Mignolo (2013: 127-131) - un programa esencialista de la historia y,por lo tanto, genotípica y fenotípicamente inherente a todo proceso social; por el contrario, la modernidad es una narrativa dominante sobre cierta perspectiva de la cultura occidental que, por su coexistencia con las bases estructurales del colonialismo, ha instaurado un imaginario-civilizador que convierte a la provincia o a diversas zonas intranacionales en un otro implícito. Entonces, ¿qué pasaría si argumentáramos a favor de la no-modernidad escénica de numerosos pueblos de nuestra nación? un dato empírico insoslayable para quienes somos asiduos espectadores en las heterogéneas comunidades teatrales del país. Un dato empírico que opera como obstáculo epistemológico en las historiografías del teatro argentino, al impugnar la categoría discrecional de "teatro premoderno" asignada a las teatralidades de pueblos y comunidades que no condicen con los parámetros estético-reduccionistas del teatro metropolitano. La noción de teatro premoderno entiende a la modernidad como una fase histórica naturalizada y garantizada para todas las territorialidades por igual, es decir, como una "flecha" programática e inamovible de la historia que apunta hacia una única dirección: el "progreso" descrito por coordenadas eurocéntricas.

En el prólogo del libro Historia del teatro argentino en las provincias Osvaldo Pellettieri, el historiador y director de este inédito proyecto académico, reconoce las paradojas de la Modernidad en el arte escénico nacional, aunque -paralelamente-ubica a las narrativas modernas como un criterio operativo para la valoración poética de las diversas geoculturas escénico-regionales, es decir, un criterio que permitiría "el tránsito de la mentalidad parroquial a la mentalidad de una verdadera comunidad teatral" (2007: 15). Al respecto, dice:

Finalmente ya dijimos que el orden y la acción son la base en la construcción de esta Historia, que toma el temor provinciano al aislamiento como la verdadera dinámica de su iniciación y su desarrollo posterior. Su teatro, aún el moderno, se basó en la elocuencia y lo pasional de sus teatristas. Pueden más ellos que lo imaginativo o lo metafórico. El teatro se nutre de aquellos, por lo tanto, lo pasional en la escena provinciana está por encima de lo metafórico. Juzgado desde el primero, el teatro resulta muy rico y desde lo segundo bastante pobre. (...) Ya en los [años] setenta se creó una cultura moderadamente moderna propia, una verdadera comunidad teatral, superadora de lo provincial, lo querencial, ya que esta cultura moderna es la cultura internacional y sólo puede ser producida y reproducida 
por los teatristas a partir de la mezcla y el intercambio con lo regional, hecho que la hace muy distinta de los intertextos internacionales (Pellettieri, 2007: 16-17).

Es precisamente esta episteme sobre lo moderno la que configura lo canónico y sus proyecciones homogeneizadoras en el "teatro del interior", dado que en dicha concepción la modernidad es un fenómeno que concibe al pensamiento europeo -y a su reproductividad cartográfica- como el centro de los sistemas culturales o, también, como un locus de enunciación fundacional de lo nuevo. Por ejemplo, una estrategia deconstructiva del vínculo de los teatros regionales no-centralizados con los paradigmas estético-modernos se observa en la revisión crítica sobre los "repertorios" (géneros, autores y títulos) de los teatros independientes emergentes en las provincias, pues, si bien existen simetrías entre los montajes escénicos realizados por formaciones independientes rioplatenses y formaciones independientes intranacionales no se puede reducir dicha simetría autoral a los complejos modos y medios de producción poética que intervinieron en dichos procesos creativos, pues éstos están anudados a variables socio estéticas localizadas, así como a singulares interrelaciones geoculturales, las que plantean una lógica territorial y diferencial específica.

Por consiguiente, se sustancia un régimen de oposición e hibridación entre lo viejo (o "la anterioridad") y lo nuevo (o "la modernidad"), entre la irracional "pasión" del folklorismo "querencial" y la metáfora racionalista de los tiempos innovadores. Los binomios simplistas decentro/periferia o metrópolis/aldea actúan como dispositivos estructurantes y hegemónicos, a partir de la incorporación del Nuevo Mundo a la cartografía local (Palermo, 2005: 90). Incluso, desde este régimen estético y geopolítico, surgen otras categorías monovalentes aplicadas a las prácticas artísticas no-centralizadas: pueblo/capital, subordinación/progreso, retraso/desarrollo, entre otras.

2. El segundo desafío epistemológico que el aforismo "soy de donde pienso" estimula en los estudios teatrales regionales es, en correlación con lo anterior, la elaboración de instrumentos teóricos que permitan captar la diversidad en la homogeneidad heredada como tradición selectiva. Es decir, se busca afianzar las instancias de auto cuestionamiento del sentido común o de la doxa cristalizada y, a su vez, se incita a la "desobediencia disciplinar" (Mignolo, 2013: 21), al exponer nuevamente las tensiones entre lo global y lo local. Por esto, en las últimas décadas se ha consolidado un marco conceptual que resulta operativo al estado actual de la historiografía de los teatros regionales de nuestro país, esto es, la estrategia de "teorizar a través de las fronteras" (Mignolo, 1991). Paralelamente, se requiere abandonar las dicotomías o los binarismos y asumir la "complejidad" (Morin, 1994) de las prácticas y discursos que conforman el objeto/problema de la investigación, mediante una concepción que ayude a la 
descentralización pero también a la desperiferización de nuestras dimensiones de análisis, admitiendo el derecho y la necesidad de la teoría e historia del teatro regional a postular su universalidad y no, únicamente, su restricción a postular "lo local de lo local". En otros términos, apelamos a una teoría que comprenda a las producciones escénico-regionales a partir de sus tensiones fronterizas, al asumir el derecho y la necesidad delos teatros regionales a decir "soy mundo" y no solo "soy aldea" (Mellado, 2015: 69).

Los reposicionamientos gnoseológicas requeridos en nuestro programa historiográfico implican, entre otros factores, indagar en la otredad manifestada sobre las prácticas y discursos regionales; pues, garantizar la reproductividad de los teatros zonales bajo la condición de "patria chica" o "nación interior" sin distinciones culturales es -como han demostrado los autores de nuestro marco de referencia- homologar la pluralidad estético-teatral a un único mecanismo de legitimación: la alteridad folklórica que ratifica al centro -o a los centros- en su lugar de poder.

La geopolítica del conocimiento organiza sus saberes a través de las fronteras culturales para operar de manera disruptiva sobre aquellas dicotomías simplistas y homogeneizadoras. Desde este posicionamiento, las fronteras indicadas actúan como instrumentos conceptuales y técnicos que contribuyen a la descentralización y a la desperiferización de los objetos de estudio porque se concentran en el "entre", esto es, un espacio de enunciación diferencial y geopolítica para la producción de pensamientos alternativos (Palermo, 2005: 103).

En suma, por efecto de las tradiciones intelectuales heredadas y de las perspectivas gnoseológicas descritas, nuestra concepción de la historiografía delos teatros argentinos será, mutatis mutandis, "interregional", construida por la puesta en diálogo de genealogías y territorialidades regionales "otras", las que permitirían cuestionar el binarismo y la homogeneización geopoéticas tradicionalistas. De este modo, regionalizar es, para nosotros, componer plexos y nodos interregionales.

Asimismo, esta resemantización (histórica, ideológica y teórica) de "lo regional" -con apropiación de la hibridez de lo provincial, lo municipal, lo pueblerino, entre otros condensadores identitarios- encuentra su fundamento en la teoría de las "configuraciones culturales" propuesta por Alejandro Grimson. En efecto, el citado antropólogo plantea analizar las formaciones interculturales "sedimentadas" (2012: 167) -en nuestro caso, el constructo teatro regional- a partir de dos operaciones: "lo erosionado" (esto es, la capacidad del tiempo histórico para disolver lo sedimentado en determinadas fases o períodos) y "lo corrosivo" (alude a las acciones y agenciamientos socioculturales que provocan rupturas en aquellas estructuras cristalizadas). 
La erosión y corrosión del teatro regional como dispositivo estético y geopolítico homogeneizado y esencialista podría deconstruirse a partir de los elementos constitutivos que, según Grimson (2012: 172-177), conforman una "configuración cultural":

a. Un "campo de posibilidad" formado por la dinámica y multiplicidad de espacios socioculturales, el cual posee -según el autor citado- representaciones, prácticas e instituciones posibles (aunque no sean mayoritarias); o representaciones, prácticas e instituciones imposibles; o representaciones, prácticas e instituciones hegemónicas (2012: 172). Desde esta perspectiva, un estudio sobre el teatro regional -0 , por lo antedicho, interregional- implicaría superar las asimetrías registradas entre territorialidades administrativas -la provincia de Neuquén- y las territorialidades teatrales, estas últimas divergentes e irreductibles a los límites geojurídicos que no equivalen a un supuesto "teatro neuquino". Entender y definir las representaciones, prácticas e instituciones teatrales como campos de posibilidades regionales abre un área de estudio que supera la indicada tradición jurídico-administrativa, pues los teatros regionales no-centralizados podrían ser conformados por singulares e inéditos "mapas de irradiación" (Dubatti, 2008: 67). Por ejemplo: si consideramos al Paralelo $42^{\circ}$ sur como una coordenada escénico-interregional, se fusionan representaciones, prácticas e instituciones de dos provincias distintas, Río Negro y Chubut, pero también de la región de Los Lagos chilena. Entonces, se configura un posible mapa teatral que excede los lindes geojurídicos predeterminados, al exigir un singular análisis de identidad productiva en esa "Iugarización". En síntesis, un teatro regional no-centralizado demandala elaboración de cartografías alternativas y diálogos interregionales, formados por distintos espacios urbanos, corredores culturales, fronteras públicas o imaginarias que, hasta la fecha, han sido silenciados por los discursos teórico-teatrales dominantes (Villegas, 2005: 25).

b. El segundo componente requerido en la teoría de las configuraciones culturales es una determinada lógica de interrelación entre las partes. Al respecto, dice Grimson:

\footnotetext{
(...) toda configuración tiene una lógica sedimentada de articulación situada de esa heterogeneidad, dispositivos que otorgan sentidos determinados a las partes. Inestables, esos sentidos son disputados justamente porque son relevantes y porque estructuran la vida social en múltiples aspectos (2012: 176).
}

Los mapas teatrales de irradiación, identificados a partir de sus relaciones temporales y diferenciales, redes y fronteras (Palermo, 2011 y 2015; Martínez, 2015) se establecen -en nuestro caso de estudio- rompiendo con la "adjetivación gentilicia" asignada por la tradición homogeneizadora nacionalista: teatro tucumano, teatro pampeano, entre otras. Por lo tanto, reproducir teóricamente esta cristalización identitaria en nuestras prácticas reflexivas conlleva a 
obturar la interrelación entre las partes que integran una región. En suma, como ha señalado con claridad la investigadora Luciana Mellado (2015) en sus estudios sobre la literatura en la Patagonia, la localidad de un artista o la residencia de una práctica creativa no pueden funcionar como un criterio epistemológico apriorístico en la compresión historiográfica y poética de una obra de arte, pues indicar que una obra teatral es -por ejemplo- "neuquina" implicaría, en primera instancia, reducir y cercenar las diversas vinculaciones que esa producción estética posee con otras representaciones, prácticas e instituciones por fuera de dicha territorialidad administrativa. Vale decir, se reproduce una identificación territorial "monovalente" que anula la "polivalencia" o riqueza intercultural e intersubjetiva que la sostiene sociohistóricamente (Mellado, 2015: 66-67). Tanto la geopolítica del conocimiento propuesta por Walter Mignolo y Zulma Palermo en sus respectivos campos disciplinares, como así también la teoría del teatro comparado desarrollada por Jorge Dubatti $(2008 ; 2011)$ han explicitado la infertilidad de los debates sobre los gentilicios de las obras de arte, esto último, al demostrar que nuestra tarea analítica es determinar topografías de origen -un punto cardinal- pero también las rutas de dispersión (redes, circuitos y fronteras interrelacionadas) por las que transita dicha obra de arte. En definitiva, un artefacto teatral construye -en sus ciclos vitales sincrónicos y diacrónicos- su propia cartografía, irreductible a la monovalente categoría de un gentilicio.

c. El tercer componente que nos permitiría entender el teatro regional como una configuración cultural es una trama simbólica común. Sobre esta cualidad, Grimson agrega:

\begin{abstract}
Allí donde no hay un mínimo de comprensión, no hay una configuración. Evidentemente cada grupo y cada actor [agente] dicen cosas muy diferentes, pero lo que enuncian es inteligible para los otros actores [agentes]. Sin duda hay interpretaciones distintas y opuestas sobre las mismas enunciaciones, pero los principios de división del mundo en términos de campo/ciudad, blancos/negros, capital/interior, ricos/pobres, ciudadanos/extranjeros $\mathrm{u}$ otros implican, necesariamente, la sedimentación de ciertos principios de (di)visión compartidos, una lógica sedimentada de la heterogeneidad que habilita e inhabilita posiciones de sujeto y lugares de enunciación (2012: 176).
\end{abstract}

De este modo, el teatro regional sería una configuración cultural resultante del pensamiento fronterizo y simbólico relacional, aquel que habilita el análisis de lindes o lugares entremedios, como así también de conflictos y de intercambios comunes, es decir, propone un locus de enunciación dinámico y diferencial en el que las identidades adquieren una geografía imaginaria, promotora de lo "compartido".

El cariz dinámico y relacional de una región es también corroborado por los avances teóricos de la geografía humana contemporánea. Puntualmente, adherimos a los aportes disciplinares 
de Sebastián Gómez-Lende, quien -entre otras características que por razones de economía argumentativa no podemos exponer en este artículo- define a lo regional por su “indeterminación escalar" (2011: 88), esto es, se impugna uno de sus rasgos tradicionalistas: la contigüidad territorial como condición necesaria para la formación de una región.

Según el relevamiento bibliográfico del citado autor, la geografía positivista ha redundado en regionalizaciones cuyas estructuras se forman a partir de enfoques sociales, económicos o naturales, mecánicamente aglutinados en esquemas reduccionistas, fundados en el criterio de la "extensión" y/o "cercanía" ofrecida por cálculos geométrico-formales (2011: 94). Sin embargo, una región no se compone -de manera ineludible- por la vecindad o proximidad de subespacios preestablecidos, por el contrario, la "distancia" geofísica entre núcleos espaciotemporales puede ser un componente sustancial de la fenomenología de una región. Respecto de esta proposición, Gómez-Lende agrega:

\begin{abstract}
Se asiste entonces al pasaje de una visión horizontal a un enfoque vertical de la región, en el que las solidaridades organizacionales convierten a los lugares en soporte y condición de relaciones globales que de otra forma no se realizarían [...] superponiéndose a los nexos y estructuras orgánicas preexistentes para reestructurar, destruir y recrear sus límites y sus duraciones, es decir, sus escalas (2011: 90).
\end{abstract}

En suma, la región es el orden espacial que le corresponde a un determinado y provisorio orden temporal. Surge de un híbrido proceso de construcción, destrucción y reconstrucción de diferencias y jerarquías territoriales, como así también de la puesta en diálogo de segmentos y nodos de producción específicos, líneas o redes de circulación y zonas reticulares, es decir, ámbitos que tienen voluntad o vocación de ser ordenadores espaciales, independientemente de su vecindad o proximidad.

Esta perspectiva teórica desencadena en las investigaciones teatrales un necesario estudio comparado (Dubatti, 2008; 2011) a partir del reconocimiento, descripción y análisis exhaustivo de la genealogías fronterizas intrarregionales e interregionales, puesto que en ellas se develarían las lógicas de las diferencias zonales y las tramas simbólicas compartidas. Además, indagar en las filiaciones y afiliaciones intrarregionales e interregionales -por fuera de la tradición administrativa que funda regiones por contigüidad- supone desligarse del imperativo monovalente antes indicado y, a su vez, contrastar nuestras reflexiones con una geografía de lo imaginario, la que contribuiría a la puesta en diálogo de territorialidades escénicas marginales, cercanas o distantes, pero con entramados simbólicos y, básicamente, con "solidaridades organizacionales" comunes. 


\section{Las implicancias geo-imaginarias en la construcción de los teatros interregionales}

Con el fin de revisitar y/o reformular los procesos de regionalización en las historiografías de los teatros argentinos, planteamos la siguiente estrategia heurística y exploratoria: dislocar los objetos de estudio hacia territorialidades alternativas dentro de los complejos esquemas político-administrativos del país, con topografías que develen las tensiones entre lo uno y lo múltiple (Guillen, 2005), sin jerarquías etnocéntricas tipificadas o unidireccionales (Buenos Aires/Jujuy, Buenos Aires/Mendoza, o similares). Vale decir, buscamos establecer redes que fracturen la naturalización del tópico centro/periferia y que develen estímulos intrarregionales e interregionales en las teatralidades marginales, esto último, con trazados geoestéticos que independientemente de sus profundas diferencias, las cuales serán componentes activos en los análisis- compartan una condición política subalternay determinadas "solidaridades organizacionales". Desde esta configuración, la región teatral no sería sólo un preconcepto legislativo, por el contrario, resultaría de los límites construidos por la lógica comparatista y polisistémica desarrollada, es decir, surgiría una concepción alternativa de lo interregional, con fronteras móviles que emergerían de los entes poético-territoriales. En otros términos, es interrogar a los artefactos escénicos por sus propios lindes y entrecruzamientos geoculturales (Palermo, 1998: 65-66).

Estos fundamentos y objetivos promueven nuevos mapas escénicos que desplieguen -como ha afirmado Djelal Kadir- "puntos cardinales" descentralizados y "mundos ordinales" con jerarquías dislocadas. En relación con estos lineamientos, el autor mencionado afirma:

[...] los códigos geográficos, es decir, las coordenadas culturales que sirven de patrón para la aculturación de un espacio, inscriben sentidos, en la connotación equívoca del término, sentidos cardinales que enmarcan horizontes no solamente geográficos, sino ordinales a la vez, que definen significados epistémicos. La cartografía inexorablemente imaginativa, engendra construcciones de realidad vivencial, de inevitable regate dialectal, ya que donde hubiera sentido, inevitablemente habrá habido, hay, y siempre habrá, contrasentido. Esto necesariamente conduce a espacios culturales simultáneos y diferenciales, cada cual con sus propios reclamos, clamores... (2002: 51).

En efecto, dislocar la noción de teatro regional a través de un estudio fronterizo o interregional exige el acceso a las formas territoriales desde axiologías dinámicas, con apertura a una dialéctica entre lo instrumental -fuente tradicional de la geografía positivista- y lo imaginario o, mejor, lo"geo-imaginario". 
Siguiendo a Jean-Jacques Wunenburger (2008: 15), entendemos "lo imaginario" como una lógica específica de la acción social, expresada en contenidos, estructuras y figuraciones, con competencias simbólicas y -de especial interés para nuestro estudio- con función poiética, lo que le permite a los sujetos actuantes elaborar categorías de adscripción y/o marcos de referencia dinámicos, pero al mismo tiempo, con anclajes geohistóricos. Asimismo, tal como expone Paul Ricoeur, imaginar es reestructurar campos de significación, para dar lugar a "conflictos semánticos" (2000: 201-202) que movilizan ciertos estamentos del tejido social.

Desde este punto de vista, los sujetos organizan, desarrollan y legitiman sus territorialidades a través de imaginarios, los que reconocen funciones subjetivas y objetivas difíciles de compilar o predeterminar. No obstante, Wunenburger plantea tres importantes perspectivas para reflexionar sobre las representaciones geo-imaginarias en el campo de los estudios teatrales interregionales. A saber:

a. Perspectiva estético-lúdica: se expresa en los juegos de diversa naturaleza y, con directa vinculación con nuestro estudio, en las prácticas artísticas. Entonces, lo imaginario -con base trascendental en el homo aestheticus- es un espacio de concreción y expansión de la intersubjetividad, por ejemplo, al crear lo posible de un mundo otro que contraste con lo empírico-cotidiano y, desde allí, permitir una emancipación simbólica (2008: 46-47).

b. Perspectiva cognitiva: en correlación con lo anterior, Wunenburger señala que "...lo imaginario puede aparecer, así, como una vía que permite pensar allí donde el saber desfallece" (2008: 49). De este modo, las representaciones imaginarias promueven pensamientos simbólicos, referenciales y analógicos, pero caracterizados por su condición plástica y dúctil, lo que obliga al analista a remitirse a los diversos soportes de sus fuentes.

c. Perspectiva instituyente práctica: en este cariz,lo imaginario no solo conforma relaciones de sensibilidad o posiciones gnoseológicas, también -dice el autor de referencia- afianza acciones objetivas en determinados marcos sociales, pues la conducta de los sujetos encuentra en la urdimbre imaginaria un sostén específico para los contenidos institucionales. Esta conceptualización operativa se vincula, además, con las demostraciones de Cornelius Castoriadis (2013: 283-299), quien analiza los "esquemas de coexistencia" -o dinámica en conjunto e interrelacional de los fenómenos sociales- y los "esquemas de sucesión" -o dinámica funcional y cambiante de las cosas, personas e ideas- desde la función ontológicoimaginaria de lo instituido y lo instituyente.

Estos fundamentos han impactado en un encuadre transdisciplinar que -desde nuestra lectura-interviene como marco teórico-auxiliar de la estrategia metodológico-teatral antedicha, 
aludimos a la denominadageografía de lo imaginario, un área con amplio desarrollo epistémico dentro de la geografía humana, el cual ofrece nuevos horizontes para pensar las regionalizaciones en la historiografía del arte. A esta resignificación imaginaria de lo regional se accede mediante instrumentos y andamiajes teórico-metodológicos para la investigación espacial de lo social, al reconocer en los imaginarios territoriales un campo fértil para nuevas articulaciones analíticas entre las escalas. Entre otras dimensiones o lineamientos, esta disciplina indaga en los mecanismos de apropiación de la naturaleza y en las identidades paisajísticas o, también, en las representaciones imaginarias sobre la otredad "geopoética" (Claval, 2012: 30) y en las proyecciones que estas figuraciones, imágenes y esquemas perceptivos poseen en las prácticas del turismo; incluso, se abordan las polimórficas relaciones sociales de la urbanidad (estructuraciones arquitectónicas, composiciones proxémicas, idealizaciones territoriales, etc.), entre otras múltiples variables de estudio. En resumen, Bernard Debarbieux nos propone una definición estratégica y correlativa con nuestros intereses, dice:

\begin{abstract}
Imaginario geográfico es un conjunto de imágenes mentales relacionadas que confieren, a un individuo o a un grupo, un significado y una coherencia en cuanto a su localización, distribución, interacción de los fenómenos en el espacio. El imaginario contribuye a organizar las concepciones, las percepciones y las prácticas espaciales (Claval, 2012: 32).
\end{abstract}

Por consiguiente, este campo de saber estimula nuevos interrogantes sobre la composición historiográfica de regiones artísticas y permite asumir los desafíos epistémicos antedichos, pues, independientemente de sus configuraciones jurídico-administrativas, se incorpora al estudio de las territorialidades escénicaslos entramados subjetivos que se tejen entre el sujeto y su hábitat. Estos lazos surgen de una medición dinámica y performática entre los agentes sociales y el lugar, un proceso por el cual los espacios y los individuos rearticulan determinados discursos, prácticas y estructuras de sentidos alternativos. Al respecto, Vincent Berdoulay afirma:

\begin{abstract}
A la luz de las anotaciones precedentes se puede plantear que el imaginario constituye un material a partir del cual se elaboran los relatos que sirven para sustentar recíprocamente a los sujetos y los lugares. En otros términos, la co-construcción del sujeto y del lugar pasa por la mediación de imaginarios geográficos. Éstos descansan en imágenes relacionadas con la materialidad perceptible en los paisajes o en los géneros de vida, pero dependen también de la actividad imaginativa del sujeto -la imaginación en acción- para recomponerlos de manera activa. Se habla así de imaginarios ligados a los lugares, a
\end{abstract}


paisajes o territorios, es decir, ligados a formas físicas y concretas, tanto como de imaginarios sociales o políticos ligados a poblaciones específicas (2012: 50).

La geografía de lo imaginario se posiciona -tal como lo indica Alicia Lindón (2012: 67)- en las antípodas de los "territorios cosificados", al asumir la vitalidad de la subjetivación del espacio. Así, el estudio de un lugar -en nuestro caso, un nodo teatral interregionalizado- abandona la tradición metodológica de las posiciones "externas y aéreas" frente al objeto cognoscible (Lindón, 2012: 68). Por el contrario, en este marco reflexivo, un lugarse nutre -por su entidad relacional- de las tramas de significaciones móviles y plásticas que se producen, circulan y distribuyen a partir de las estructuras imaginarias instituidas e instituyentes, hasta "anudar" sentidos particulares en particulares dimensiones cronotópicas.

Si una región teatral renuncia a su condición de territorio-cosa, entonces, ladislocación de jerarquías ordinales y la "lugarización" se convierten en operaciones concordantes con la configuración histórico-cultural de prácticas y discursos escénico-regionales no centralizados.Esta perspectiva conlleva a dos intersecciones analíticas (Lindón, 2012: 75-80): primero, la interacción entre los imaginarios espaciales y las prácticas espaciales; segundo, los imaginarios espaciales según su lógica narrativa, siendo los discursos teatrales uno de sus dispositivos de despliegue.

Por el alcance de estas intersecciones analíticas es factible comprender, como ha estudiado Perla Zusman (2013) y Carla Lois (2015), la función de los imaginarios geográficos en el diseño, integración y/o control territorial. Vale decir, la regionalización incorpora a sus mapeos las representaciones de los Andes como muralla; la distinción imaginaria entre el desierto patagónico o el norteño; la fertilidad asociada con lo subtropical o la condición de frontera interna asignadas a las zonas mediterráneas del país -por ejemplo, Córdoba como "el rostro anticipado de la Nación" (Tcach, 2012)-, entre otras figuraciones que operan por su fuerza narrativa en múltiples programa territoriales: desde mapas políticos hasta cartografías artísticas.

En correlación con estas indagaciones nocionales, podemos citar el caso de la Ley Nro. 24800 de 1998, también llamada Ley Nacional del Teatro, un constructo jurídico que estipula determinadas cartografías teatrales para la ejecución de políticas de Estado. Su esquema de regionalización -dividido en seis fracciones administrativas: Centro, Centro-Litoral, Cuyo, Noroeste, Noreste y Patagonia- expone, precisamente, algunos problemas teóricos e historiográficos factibles de ser analizados por los encuadres reflexivos desarrollados, por ejemplo: la tendencia a la homogeneización de las diferencias poético-zonales en la aplicación de acciones y subsidios únicos o indiferenciados, los que no permiten consolidar las identidades estético-productivas; la instauración de un modelo de legitimación cultural 
centralizado; la obturación burocrática del ejercicio interregional de solidaridades organizacionales entre colectivos y agentes de jurisdicciones no-contiguas; la sedimentación del discurso del "otro interior" como alteridad de lo nacional plasmada, entre otras instancias, en la Fiesta Nacional del Teatro, entre otros cuestionamientos.

En consecuencia, esta y otras instancias de regionalización del campo escénico argentino podrían, desde las coordenadas epistémicas enunciadas, materializar nuevos y actuales objetos de estudio, al cartografiar territorialidades que no reproduzcan valores etnocéntricos, pues estos ineludiblemente convierten a las historias teatrales regionales en una sinécdoque de las historias teatrales metropolitanas. Al mismo tiempo, esta estrategia posee una evidente motivación político-identitaria: descentralizar y desperiferizar las teorías del arte en general y del teatro en particular es, seguidamente, construir narrativas epistemológicas y discursos de alteridad, con el fin de aportar a la dinámica de los procesos intersubjetivos en las distintas instancias de democratización del conocimiento en el país.

\section{Bibliografía}

Acha, J.; Colombres, A. y Escobar, T. (1991). Hacia una teoría americana del arte. Buenos Aires: Ediciones del sol.

Berdoulay, V. (2012). El sujeto, el lugar y la mediación del imaginario. En Lindón, A. y Hiernaux, D. Geografías de lo imaginario (pp. 49-65). Barcelona: Anthropos-Universidad Autónoma Metropolitana,

Castoriadis, C. (2013). La institución imaginaria de la sociedad. Buenos Aires: Tusquets.

Claval, P. (2012). Mitos e imaginarios en geografía. En Lindón, A. y Hiernaux, D. Geografías de lo imaginario (pp. 29-48). Barcelona: Anthropos-Universidad Autónoma Metropolitana.

Demaría, L. (2014). Buenos Aires y las provincias. Relatos para desarmar. Rosario: Beatriz Viterbo Editora.

Dubatti, J. (2008). Cartografía teatral. Introducción al teatro comparado. Buenos Aires: Atuel.

Dubatti, J. (2011). Introducción a los estudios teatrales. México DF: Libros de Godot.

Finzi, A. (1992). Teatro argentino, una estética para el fin de siglo. Espacio de crítica e investigación teatral, 6(11), pp. 51-56.

Gómez-Lende, S. (2011). Región y regionalización. Su teoría y su método. El nuevo orden espacial del territorio argentino. Tiempo y Espacio, 26, pp. 83-122.

Grimson, A. (2012). Los límites de la cultura. Crítica de las teorías de la identidad. Buenos Aires: Siglo XXI. 
Guillén, C. (2005). Entre lo uno y lo diverso. Introducción a la literatura comparada (ayer y hoy). Barcelona: Tusquets.

Heredia, P. (2012). Propuesta para un estudio de las operaciones políticas de regionalización cultural en la literatura argentina. En Massara, L.; Guzmán, R. y Nallin, A. (Eds.). Literatura del Noroeste Argentino. Reflexiones e investigaciones (volumen II) (pp. 1934). S. S. de Jujuy: Universidad Nacional de Jujuy.

Kadir, D. (2002). Puntos cardinales, mundos ordinales, literatura comparada. En Martínez Fernández, J. et al. (Eds.). Estudios de literatura comparada. Norte y Sur. La sátira. Transferencia y recepción de géneros y formas textuales (pp. 43-57). León: Universidad de León.

Lindón, A. (2012). ¿Geografías de lo imaginario o la dimensión imaginaria de las geografías del Lebenswelt? En Lindón, A. y Hiernaux, D. Geografías de lo imaginario (pp. 66-85). Barcelona: Anthropos-Universidad Autónoma Metropolitana.

Lois, C. (2015). Un mapa para la nación argentina. Notas para una interpretación crítica de la historia del mapa político y de las políticas cartográficas. Revista Huellas, 19, pp. 193215.

Martínez, A. T. (2015). ¿Prólogo o post-scriptum? En Redes intelectuales, itinerarios e identidades regionales en Argentina (Siglo XX) (pp. 13-29). Rosario: ProhistoriaUniversidad Nacional de La Pampa.

Mellado, L. (2010). La Patagonia y su literatura: unidad y diversidad multiforme. Comodoro Rivadavia, Argentina: Universidad Nacional de la Patagonia San Juan Bosco.

Mellado, L. (2015). La Patagonia como versión de una distancia. Revista Alpha, 41, pp. 65-71.

Mignolo, W. (1991). Teorizar a través de las fronteras culturales. Revista de crítica literaria latinoamericana, XVII(33), pp. 103-112.

Mignolo, W. (2003). Historias locales/diseños globales. Colonialidad, conocimientos subalternos y pensamiento fronterizo. Madrid: Akal.

Morin, E. (1994). Introducción al pensamiento complejo. Barcelona: Gedisa.

Ocampo, B. (2005). La nación interior. Canal Feijóo, Di Lullo y los Hermanos Wagner. Buenos Aires: Antropofagia.

Palermo, Z. (1998). Historiografía, literatura y región. Revista Silabario, I(1), pp. 61-74.

Palermo, Z. (2005). Desde la otra orilla. Pensamiento crítico y políticas culturales en América Latina. Córdoba: Alción.

Palermo, Z. (2011). ¿Por qué vincular la literatura comparada con la interculturalidad? En Crolla, A. (Comp.). Lindes actuales de la Literatura Comparada (pp. 126-136). Santa Fe: Universidad Nacional del Litoral. 
Palermo, Z. (2015). Fronteras del saber y construcción de identidades en los bordes. Revista Silabario, XVII(17/18), pp. 15-32.

Pellettieri, O. (2007). Qué es una historia del teatro argentino (II). En Pellettieri, O. (Dir.) Historia del teatro argentino en las provincias (volumen II) (pp. 11-17). Buenos Aires: GalernaInstituto Nacional del Teatro.

Ricoeur, P. (2000). Del texto a la acción. Ensayos de hermenéutica II. Buenos Aires: Fondo de Cultura Económica.

Tcach, C. (2012). De la Revolución Libertadora al Cordobazo. Córdoba, el rostro anticipado del país. Buenos Aires: Siglo XXI.

Villegas, J. (2005). Historia multicultural del teatro y las teatralidades en América Latina. Buenos Aires: Galerna.

Williams, R. (1980). Marxismo y literatura. Barcelona: Península.

Wunenburger, J. J. (2008). Antropología del imaginario. Buenos Aires: Ediciones del sol.

Zusman, P. (2013). La geografía histórica, la imaginación y los imaginarios geográficos. Revista de Geografía Norte Grande, 54, pp. 51-66. 